\title{
Nitriding of High Speed Steel for Improvement of Tools Resistance
}

\author{
Larisa Petrova ${ }^{1}$, Victor Vdovin ${ }^{1}$, Peter Demin ${ }^{1, a^{*}}$ and Alexandra Sergeeva ${ }^{1}$ \\ ${ }^{1}$ MADI University, Technology of structural materials department, 125319 Leningradskiy \\ prospect 64 Moscow, Russia \\ apetr-demin@yandex.ru
}

Keywords: Nitriding, High Speed Steel, Tool Resistance, Phase Composition, Hardening

\begin{abstract}
The article is devoted to the study of the gas nitriding process, which makes it possible to obtain high-quality diffusion layers in high-speed steel M2 on the basis of an internal nitriding zone without a brittle nitride zone. The results of studies of the nitrided steel phase composition with a change of the saturating atmosphere during dilution of ammonia by hydrogen are presented. An increase in the resistance of the nitrided tool when drilling structural steel is shown, which is associated with the dispersion hardening of the internal nitriding zone with tungsten nitrides.
\end{abstract}

\section{Introduction}

Today, the constantly developing industry is tightening the requirements for the service life of tools designed for processing various machine parts and devices. The most stringent requirements are imposed on tools made of high-speed steels (HSS) [1-2], working in complex conditions where high wear resistance and heat resistance are required along with resistance to shock loads. Increasing the durability of a high-speed tool contributes to resource saving, since it provides savings in metals used for alloying steels, such as tungsten and molybdenum, which makes it relevant to research on improving technologies for hardening the cutting parts of the tool. The advantages of surface hardening are not only in reducing the consumption of alloying elements, but also in maintaining a ductile core, which provides resistance to shock loads.

Currently, many different methods of surface hardening of the tool are used, which have their advantages and disadvantages [3-5]. An unique position among such processes is occupied by chemical-thermal treatment (CTT) [6-7]. For example, nitriding is widely used to increase the reliability and durability of a wide range of steels, both structural and tool [8-9]. One of the main advantages of the nitriding process is the ability to control the nitrided layers phase composition in various steels, depending on the required surface properties. The structure of the diffusion layer is regulated by controlling the nitrogen potential of the saturating atmosphere. The advantage of the process in relation to high-speed steels is a relatively low saturation temperature, which makes it possible to preserve the core structure formed by the basic heat treatment.

The optimal phase composition of the nitrided cutting edge, which provides the necessary tool durability, differs depending on the cutting conditions, the type and size of the tool, as well as on the material being processed. To prevent the compact nitrides zone formation at the surface, technological techniques based on changes in the nitrogen potential of the atmosphere are used: dilution of ammonia, for example, with an inert gas, hydrogen or with products of ammonia dissociation.

The purpose of this work is to study the structure of the nitrided layer in high-speed steel during nitriding in ammonia and hydrogen, as well as to determine the composition of the saturating atmosphere to increase the drills durability. 


\section{Methods of experimental study}

The studies were carried out on samples and drills with a diameter of $5 \mathrm{~mm}$ made of high-speed tool steel HSS M2, the chemical composition of which according to ASTM A600 Standard is given in the Table 1.

Table 1. Chemical composition of M2 steel

\begin{tabular}{|c|c|c|c|c|c|c|c|}
\hline Element & $\mathrm{C}$ & $\mathrm{Cr}$ & $\mathrm{V}$ & $\mathrm{Mo}$ & $\mathrm{W}$ & $\mathrm{P}$ & $\mathrm{S}$ \\
\hline Weight \% & $0.78-0.88$ & $3.75-4.50$ & $1.75-2.20$ & $4.50-5.50$ & $5.50-6.75$ & 0.03 & 0.03 \\
\hline
\end{tabular}

Steel samples and drills were used in the condition after standard heat treatment. Quenching from $1250^{\circ} \mathrm{C}$ and triple tempering at $560^{\circ} \mathrm{C}$ forms the structure of the steel cutting edge with dispersed tungsten carbides in solid solution (Fig. 1a).

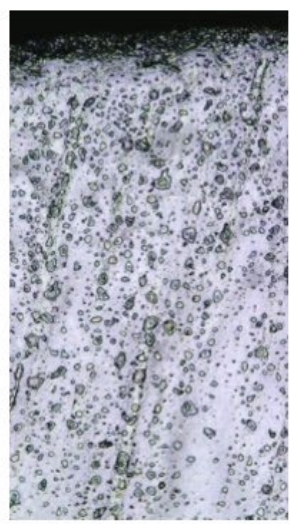

a)

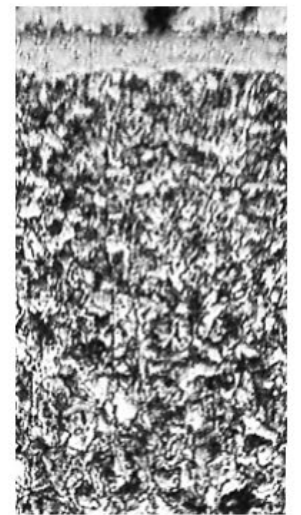

b)

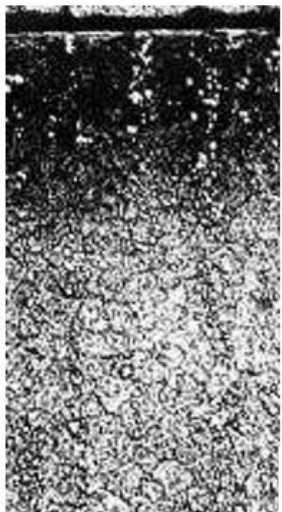

c)

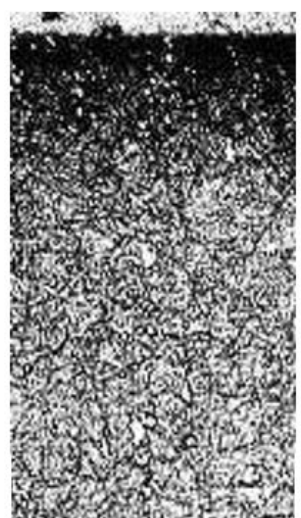

d)

Fig. 1. Microstructure of M2 steel after standard heat treatment (a) and after nitriding in pure ammonia (b), in a mixture of $75 \% \mathrm{NH}_{3}+25 \% \mathrm{H}_{2}(\mathrm{c})$, in a mixture of $50 \% \mathrm{NH}_{3}+50 \% \mathrm{H}_{2}(d)$

Nitriding was carried out on a laboratory equipment in a muffle furnace comprising a nitriding reactor. Process temperature of $540^{\circ} \mathrm{C}$ was selected below the tempering temperature to keep the matrix hardness at the initial level. Saturation was carried out in mixtures of ammonia and hydrogen; variation in the degree of ammonia dissociation was achieved by changing the hydrogen content in the atmosphere $\left(25 \% \mathrm{H}_{2}, 50 \% \mathrm{H}_{2}\right.$, and $\left.75 \% \mathrm{H}_{2}\right)$. The regulation of the gas mixtures composition in the furnace was carried out using a control unit for the dosing of gas components. The atmosphere composition at the entrance and the temperature in the furnace were set using software and maintained automatically using the control of the process technological parameters.

The nitrided steel microstructure was studied by metallographic analysis using an Axiovert 25 CA optical microscope after electrolytic etching of microsections in an aqueous solution of oxalic acid. Studies of the substructure and layer phase composition were carried out by electron microscopy (SMM 2000), scanning probe microscopy (SPM NanoEducator) after electrolytic etching and by X-ray diffraction analysis (DRON-3). Identification of precipitations, determination of their size and volume fraction were carried out using images on micro-diffraction patterns and dark-field images obtained in the corresponding reflexes. X-ray examinations were taken in monochromatic $\mathrm{Fe}_{\mathrm{Ka}}$ radiation.

A comparative assessment of the drills service life with different nitrogen potential was carried out by the method of studying the degree of bluntness during cutting holes by recording sound using a microphone fixed to the workpiece. During the mechanical processing of carbon steel sheet $(0.2 \% \mathrm{C})$ with a thickness of $2 \mathrm{~mm}$ on a drilling machine, sound waves were recorded on a personal 
computer. The number of holes made by the drill until blunting $(\mathrm{N})$ was determined before the appearance of a specific sound when the critical value of the amplitude of sound vibrations was exceeded.

\section{Results and discussion}

Nitriding of high-speed steel in pure ammonia forms a brittle nitride zone on the surface (Fig. 1b). This layer easily crumbles during cutting, which leads to catastrophic destruction of the cutting edge. Therefore, nitriding processes were carried out in diluted ammonia to determine the conditions under which a nitride zone does not form.

To determine the saturation time to obtain a layer of a given thickness, studies of the nitriding process kinetics in atmospheres of various compositions were carried out, and corresponding nomograms were obtained. For example, it takes 1 hour to form a diffusion layer with a thickness of $50 \mu \mathrm{m}$ when nitriding in a mixture of $50 \% \mathrm{NH}_{3}+50 \% \mathrm{H}_{2}$ (Fig. 2).

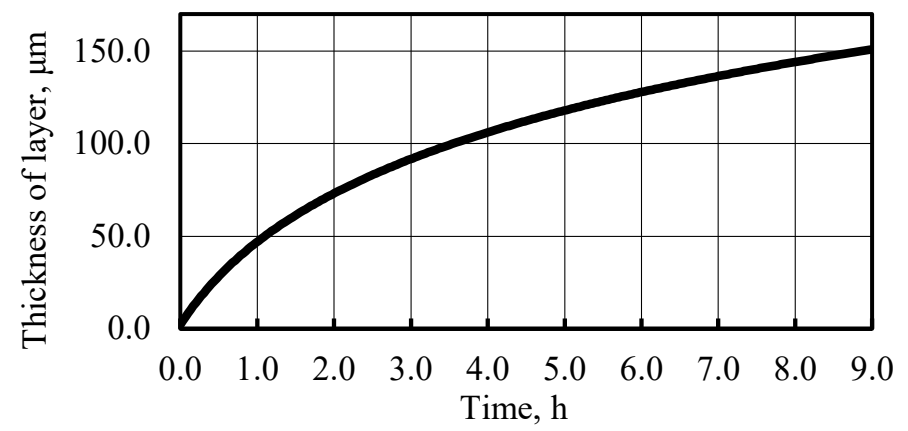

Fig. 2. Nomogram for determination of diffusion layer thickness during nitriding in $50 \% \mathrm{NH}_{3}+50 \% \mathrm{H}_{2}$ depending on saturating time.

It is known that the saturating atmosphere composition during nitriding is related to the nitrogen potential of the atmosphere $\pi_{\mathrm{N}}$, which is determined by the partial pressures ratio of hydrogen and ammonia in the system. Formation of phases in the nitrided layer depends on the nitrogen potential and the process temperature. According to the known regularities, nitriding with a low nitrogen potential (in highly dilute ammonia) may form nitrided layers of $\alpha$-solid solution without a surface nitride zone. With an increase in the nitrogen potential, ferrous nitrides are formed in order of increasing nitrogen content: $\gamma^{\prime}-\mathrm{Fe}_{4} \mathrm{~N} \rightarrow \varepsilon-\mathrm{Fe}_{2-3} \mathrm{~N}$. Table 2 shows the phases identified by X-ray analysis on the surface of M2 steel nitrided in various mixtures of ammonia with hydrogen. In Fig. 1c the nitride zone of $\varepsilon^{+} \gamma^{\prime}$ is observed, formed in the steel saturated in a mixture of $75 \% \mathrm{NH}_{3}+25 \% \mathrm{H}_{2}$. When nitriding in a mixture of $50 \% \mathrm{NH}_{3}+50 \% \mathrm{H}_{2}$, a nitride zone is not discovered in the microstructure (Fig. 1d).

Due to the high concentration of carbon and alloying elements in the M2 steel, the area of $\gamma^{\prime}-$ phase existence significantly narrows, and the area of $\alpha$-phase expands, while the thermodynamic possibility of formation of alloying elements nitrides appears. No alloying elements' nitrides were detected directly on the surface, whereas in the internal nitriding zone at a distance of 10 microns from the surface, nanoparticles of tungsten nitrides (no more than $10 \mathrm{~nm}$ ) are determined in solid solution (Fig. 3). Reflexes of $\alpha$-phase (335) and of WN nitride (001) are indicated on X-ray pattern. Such a structure of the internal nitriding zone is a prerequisite for the internal nitriding zone dispersed strengthening. 
Table 2. Phase composition of the nitrided surface on M2 steel

\begin{tabular}{|c|c|}
\hline $\begin{array}{l}\text { Saturation } \\
\text { environment }\end{array}$ & Phases on the nitrided surface \\
\hline Without nitriding & - \\
\hline $100 \% \mathrm{NH}_{3}$ & $\varepsilon-\mathrm{Fe}_{2-3} \mathrm{~N}$ \\
\hline $75 \% \mathrm{NH}_{3}+25 \% \mathrm{H}_{2}$ & $\varepsilon-\mathrm{Fe}_{2-3} \mathrm{~N}+\gamma^{\prime}-\mathrm{Fe}_{4} \mathrm{~N}+\mathrm{Fe}_{\alpha}(\mathrm{N})$ \\
\hline $50 \% \mathrm{NH}_{3}+50 \% \mathrm{H}_{2}$ & $\gamma^{\prime}-\mathrm{Fe}_{4} \mathrm{~N}+\mathrm{Fe}_{\alpha}(\mathrm{N})$ \\
\hline $25 \% \mathrm{NH}_{3}+75 \% \mathrm{H}_{2}$ & $\mathrm{Fe}_{\alpha}(\mathrm{N})$ \\
\hline
\end{tabular}

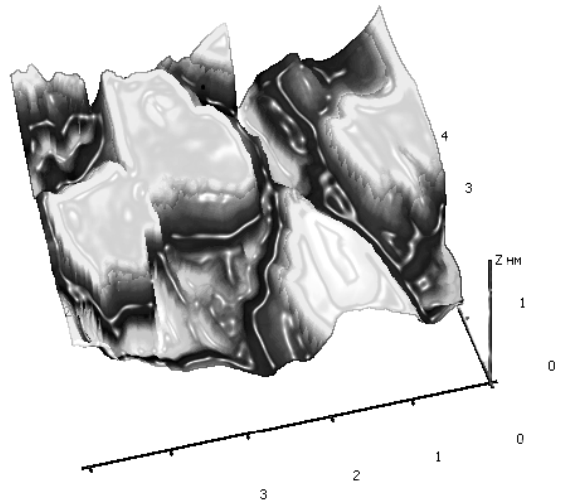

Fig. 3. Detection of tungsten nitride particles in the nitrided layer of M2 steel by SEM

Fig. 4 shows a comparison of drill resistance by the number of drilled holes measured during drilling tests. In general, the service life of drills, estimated by the sound change when drilling holes, increases after nitriding in ammonia-hydrogen mixtures. The operating time of a drill until the specific sound of blunting depends on the composition of the saturating atmosphere, i.e. it is determined by the nitrided layer phase composition.

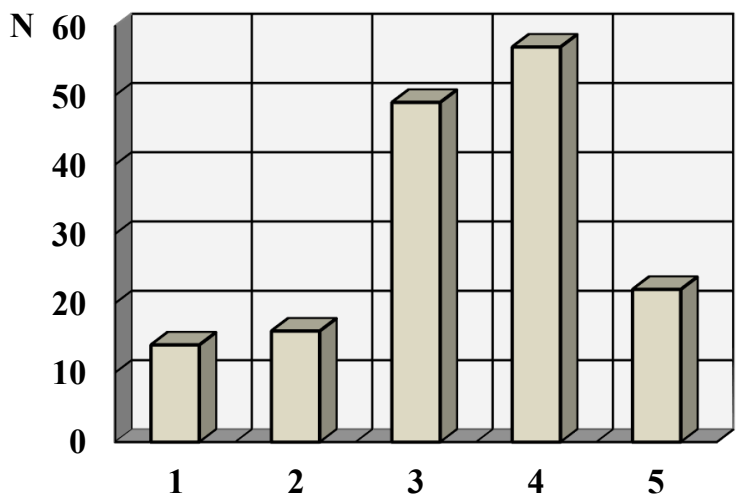

Fig. 4. Comparison of drills resistance (numbers of drilled holes until blunting): 1 - non-nitrided drill; nitrided in: $25 \% \mathrm{NH}_{3}+75 \% \mathrm{H}_{2}$ (2), $50 \% \mathrm{NH}_{3}+50 \% \mathrm{H}_{2}$ (3), $75 \% \mathrm{NH}_{3}+25 \% \mathrm{H}_{2}$ (4), $100 \% \mathrm{NH}_{3}$

The sound amplitude during drilling reaches a critical value faster when using a non-nitrided drill, which has a minimum resistance index. Drills with the nitrided layer without a surface nitride zone formed in an atmosphere of $25 \% \mathrm{NH}_{3}+75 \% \mathrm{H}_{2}$ increase the durability of the drill slightly. Drills nitrided in pure ammonia also do not provide a large increase in durability, since they have a brittle $\varepsilon$-phase zone on the surface, which quickly cleaves off during drilling. Drills nitrided in 
$75 \% \mathrm{NH}_{3}+25 \% \mathrm{H}_{2}$, having the nitride zone of $\varepsilon+\gamma$, work the longest before blunting; their resistance is 4 times higher comparing to un-nitrided tool.

\section{Conclusion}

Nitriding process of high-speed steel at $\mathrm{t}=540^{\circ} \mathrm{C}$ is investigated in mixtures of ammonia and hydrogen. The nitriding modes are determined that from diffusion layers of an internal nitriding zone with precipitation of dispersed tungsten nitrides and without brittle $\varepsilon$-phase zone at the surface. Nitriding in this mode significantly increases the durability of drills, due to the dispersion hardening of the internal nitriding zone. The tools nitrided in ammonia diluted with $25 \% \mathrm{H}_{2}$ and with $50 \% \mathrm{H}_{2}$ has the best resistance. Strong dilution of ammonia $\left(25 \% \mathrm{NH}_{3}+75 \% \mathrm{H}_{2}\right)$ significantly reduces the nitriding effect, which is associated with a small layer thickness and a low level of solid solution hardening.

\section{Acknowledgments}

The material was prepared within the framework of scientific research under the project №FSFM2020-0011 (2019-1342); experimental studies were carried out using the equipment of the MADI Centre of collective usage.

\section{References}

[1] L.S. Kremnev From high-speed tungsten steel to high-temperature molybdenum steel: a century of high-speed steel/Steel in Translation. 2009. T. 39. № 12. pp. 1111-1118. https://doi.org/10.3103/S0967091209120195

[2] A.S. Chaus, M. Dománková Unknown high-speed steel/Materials Letters. 2021. T. 292. pp. 129653. https://doi.org/10.1016/j.matlet.2021.129653

[3] Y. Li, G. Zhang, J. Yao, F. Xiao,Y. Wang, Y. Liu M2 High speed steel irradiated by highintensity pulsed ion beam/Cailiao Yanjiu Xuebao. 2005. T. 19. № 6. pp. 613-618.

[4] V.I. Yurshev, R.I. Mukatdarov, I.V. Yurshev Surface hardening of tools by depositing a pyrolytic chromium carbide coating, Metal Science and Heat Treatment. 2015. T. 57. № 1. pp. 107-111. https://doi.org/10.1007/s11041-015-9845-y

[5] A. Vereschaka, A. Aksenenko, S. Shevchenko, et al. Effect of adhesion and tribological properties of modified composite nano-structured multi-layer nitride coatings on WC-Co tools life/Tribology International. 2018. T. 128. pp. 313-327.

https://doi.org/10.1016/j.triboint.2018.07.039

[6] U. Tolibjon Hardening high-speed steel R6M5 using a combined heat treatment technology/Lecture Notes in Networks and Systems. 2022. T. 305. pp. 153-161. https://doi.org/10.1007/978-3-030-83368-8_15

[7] V.A. Aleksandrov, L.G. Petrova, A.S. Sergeeva, V.D. Aleksandrov, E.U. Akhmetzhanova Production of tool coatings by chemicothermal plasma methods, Russian Engineering Research. 2019. T. 39. № 8. pp. 693-695. https://doi.org/10.3103/S1068798X19080033

[8] I.S. Belashova, L.G. Petrova, V.D. Aleksandrov, P.E. Demin. Improving the properties of low-alloy and carbon steel tools by cyclic nitriding, Russian Engineering Research. 2018. T. 38. № 1. pp. 53-56. https://doi.org/10.3103/S1068798X18010057

[9] P.L.C. Serra, A.S.A. Furtado, R.R.M. de Sousa, J.R. de Barros Neto, W.R.V. Sampaio, M.C. Feitor, T.H. de Carvalho, Costa Study of plasma nitriding and duplex treatment on high speed steel drills/Revista Materia. 2020. T. 25. № 2. pp. 1-15. https://doi.org/10.1590/s1517707620200002.1072 